\title{
KURIKULUM PENDIDIKAN AGAMA BERBASIS MULTIKULTURAL
}

\author{
Abdul Khoir Hs \\ Universitas Islam 45 Bekasi \\ Email; juragankhoir2@gmail.com
}

\begin{abstract}
Abstrak
Tulisan ini adalah sumbangsih pemikiran untuk menyadarakan dunia pendidikan untuk terus menerus memperhatikan pentingnya menanamkan sikap toleransi pada siswa. Mengingat kemajemukan etnis dalam interaksi social adalah keniscayaan. Interkasi dengan meniadakan sikap intolerasi pada suku, agama dan ras menjadikan hidup penuh warna (multikultur/ pluralis). Agama hadir hanya untuk mendiskriditkan kezoliman dan keangkaramurkaan, melaikan untuk mewujudkan kedamaian. Pendidikan agama sejatinya menanamkan sikap toleransi dalam keniscayaan akan multicultural. Disitulah pentingnya kurikulum Pendidian Agama di desain untuk melahirkan manusia terdidik yang toleran dengan perbedaan.
\end{abstract}

Kata Kunci: Kurikulum, Pendidikan Agama, Multikultural

\section{Pendahuluan}

Era sekarang adalah era multikulturalisme dan pluralisme, dimana seluruh masyarakat dengan segala unsurnya dituntut untuk saling tergantung dan menanggung nasib secara bersama-sama demi terciptanya perdamaian abadi. Salah satu bagian penting dari konsekuensi tata kehidupan global yang ditandai kemajemukan etnis, budaya, dan agama tersebut, adalah membangun dan menumbuhkan terus menerus sikap hidup bersama dengan keragaman budaya (multiculturalisme) atau dapat diartikan sebagai hidup dengan sikap pluralisme.

Demi tujuan itu, maka pendidikan sebenarnya masih dianggap sebagai instrumen penting. Sebab, pendidikan sampai sekarang masih diyakini mempunyai peran besar dalam membentuk karakter individu-individu yang dididiknya, dan mampu menjadi "guiding light" bagi generasi muda penerus bangsa. Mengembangkan pola pendidikan berbasis multikultur diharapakn mampu mengakomodasi kebutuhan manusia akan hidup bersama dalam keragaman. Beberapa pakar pendidikan menjelaskan pendidikan multukultural diartikan sebagai pendidikan mengenai keragaman kebudayaan. Andersen dan Cusher (1994: 320). Hilda Hernandez mengartikan pendidikan multikultural sebagai perspektif yang mengakui realistis politik, sosial, dan ekonomi yang dialami oleh masingmasing individu dalam pertemuan manusia yang komplek dan beragam secara kultur dan merefleksikan pentingnya budaya, ras,gender, etnisitas, agama, status sosial. Sedangkan HAR Tilaar fokus dari pendidikan multikultural adalah sikap peduli dan mau mengerti (politik pengakuan terhadap orang-orang dari kelompok minoritas).

Dalam struktur kurikulum pendidikan di Indoensia, program studi Pendidikan Agama adalah yang paling signifikan dalam menumbuhkan sikap kehidupan bersama dalam keragaman multikultutral atau pluraris. Pendidikan 
agama sebagai media penyadaran umat dalam membangun kesadara kolektif akan keniscayaan multikultular demi harmonisasi kehudupan.

Mengapa pendidikan agama? Salah satu peran dan fungsi pendidikan agama diantaranya adalah untuk meningkatkan keberagamaan peserta didik dengan keyakinan agama sendiri, dan memberikan kemungkinan keterbukaan untuk mempelajari dan mempermasalahkan agama lain sebatas untuk menumbuhkan sikap toleransi (Sealy, 1986: 43-44). Ini artinya, pendidikan agama pada prinsipnya, juga ikut andil dan memainkan peranan yang sangat besar dalam menumbuhkembangkan sikap-sikap pluralisme dalam diri siswa.

Apalagi, kalau mencermati pernyatan yang telah disampaikan oleh Alex R. Rodger (1982: 61) bahwa "pendidikan agama merupakan bagian integral dari pendidikan pada umumnya dan berfungsi untuk membantu perkembangan pengertian yang dibutuhkan bagi orang-orang yang berbeda iman, sekaligus juga untuk memperkuat ortodoksi keimanan bagi mereka". Artinya pendidikan agama adalah sebagai wahana untuk mengekplorasi sifat dasar keyakinan agama di dalam proses pendidikan dan secara khusus mempertanyakan adanya bagian dari pendidikan keimanan dalam masyarakat. Pendidikan agama dengan begitu, seharusnya mampu merefleksikan persoalan pluralisme, dengan mentransmisikan nilai-nilai yang dapat menumbuhkan sikap toleran, terbuka dan kebebasan dalam diri generasi muda.

Untuk membangun dan menumbuh kembangkan sikap pluralisme dalam masyarakat, maka inovasi dan pengembangan kurikulum Pendidikan Agama perlu dilakukan karena sifat kurikulum yang dinamis, selalu berubah, menyesuaikan diri dengan kebutuhan pemelajar. Mereka yang belajar mengalami perubahan maka langkah awal dalam perumusan kurikulum ialah penyelidikan mengenai situasi (situation analysis) yang kita hadapi, termasuk situasi lingkungan belajar dalam artian menyeluruh, situasi peserta didik, dan para calon pengajar yang diharapkan melaksanakan kegiatan.

S. Nasution mengetengahkan empat faktor landasan ataupun azas utama yang selalu mengambil peran dalam pengembangan kurikulum, yakni: pertama, azas filosofis, termasuk filsafat bangsa, masyarakat dan sekolah serta guru-guru; kedua, azas sosiologis, menyangkut harapan dan kebutuhan masyarakat (orangtua, kebudayaan, masyarakat, pemerintah, ekonomi); ketiga, azas psikologis yang terkait dengan taraf perkembangan fisik, mental, emosional dan spiritual anak didik; keempat, azas epistemologis, berkaitan dengan konsep kita mengenai hakekat ilmu pengetahuan

Melalui pengembangan kurikulum pendidikan agama berbasis kemajemukan (multikulturalisme) akan dapat dijadikan sebagai jawaban atau solusi alternatif bagi keinginan untuk merespon persoalan-persoalan di atas. Sebab dalam pendidikanya, pemahaman agama yang hendak dikembangkan oleh pendidikan berbasis pluralisme adalah pemahaman dan pemikiran yang bersifat inklusif.

Melalui sistem pendikikanya, sebuah pendidikan yang berbasis pluralisme akan berusaha memelihara dan berupaya menumbuhkan pemahaman yang inklusif pada peserta didik. Dengan suatu orientasi untuk memberikan penyadaran terhadap para peserta didiknya akan pentingnya saling menghargai, menghormati dan bekerja sama dengan agama-agama lain.

\section{Masalah dalam Pendidikan Agama}

Persoalan SARA yang muncul di wilayah Indonesia akhir-kahir merupakan akumulasi dari kegagalan agama dalam memainkan perannya sebagai problem 
solver bagi persoalan tersebut. Persoalan tersebut muncul erat kaitanya dengan pengajaran agama secara ekslusif. Maka, agar bisa keluar dari kemelut yang mendera bangsa Indonesia terkait persoalan SARA, maka sudah saatnya bagi bangsa Indonesia untuk memunculkan wajah pendidikan agama yang inklusif dan humanis.

Pada tataran teologis, dalam pendidikan agama perlu mengubah paradigma teologis yang pasif, tekstualis, dan ekslusif. Menuju teologi yang saling menghormati, saling mengakui eksistensi, berfikir dan bersikap positif, serta saling memperkaya iman. Hal ini dengan tujuan untuk membangun interaksi umat beragama dan antarumat beragama yang tidak hanya berkoeksistensi secara harmonis dan damai, tetapi juga bersedia aktif dan pro-aktif kemanusiaan.

Suatu realita bahwa bangsa kita adalah bangsa dengan berbagai keragaman sosial, budaya, ekonomi, dan aspirasi politik, dan kemampuan ekonomi masyarakat. Namun keragaman tersebut seharusnya menjadi faktor yang diperhitungkan dalam penentuan filsafat, teori, visi, pengembangan dokumen, sosialisasi kurikulum, dan pelaksanaan kurikulum, nampaknya faktor ini belum dijadikan sebagai pertimbangan dalam pelaksanaan kurikulum pendidikan di negara kita" (Hasan, 2000: 511). Maka, akibatnya, wajar manakala terjadi kegagalan dalam pendidikannya (termasuk pendidikan agama), terutama sekali dalam menumbuhkan sikap-sikap untuk menghargai adanya perbedaan dalam masyarakat.

Selain itu, Kautsar Azhari Noer (2001) menyebutkan, ada empat faktor penyebab kegagalan pendidikan agama dalam menumbuhkan sikap hidup bersama dengan multikultur/ pluralis. Pertama, penekananya pada proses transfer ilmu agama ketimbang pada proses transformasi nilai-nilai keagamaan dan moral kepada anak didik; kedua, sikap bahwa pendidikan agama tidak lebih dari sekedar sebagai "hiasan kurikulum" belaka, atau sebagai "pelengkap" yang dipandang sebelah mata; ketiga, kurangnya penekanan pada penanaman nilai-nilai moral yang mendukung kerukunan antaragama, seperti cinta, kasih sayang, persahabatan, suka menolong, suka damai dan toleransi; dan keempat, kurangnya perhatian untuk perhatikan untuk mempelajari agama-agama lain (Noer dalam Sumartana, 2001: 239-240).

Melihat realitas tersebut, bahkan ditambah dengan adanya banyak konflik, kekerasan, dan bahkan kekejaman yang dijalankan atas nama agama, sebagaimana tersebut di atas, seharusnyalah yang menjadi tujuan refleksi atas pendidikan agama adalah mampu melakukan transformasi kehidupan beragama itu sendiri dengan melihat sisi ilahi dan sosial-budayanya. Pendidikan agama harus mampu menanamkan cara hidup yang lebih baik dan santun kepada peserta didik. Sehingga sikap-sikap seperti saling menghormati, tulus, dan toleran terhadap keanekaragaman agama dan budaya dapat tercapai di tengah-tengah masyarakat plural.

\section{Pengembangan Kurikulum Pendidikan Agama}

Jika pengembangan kurikulum pendidikan agama penting untuk dikerjakan, maka pertanyaan sekarang ialah: Bagaimanakah prinsip kerja kita dalam mengembangkan kurikulum itu? Meminjam pemikiran Nana Syaodih Sukmadinata, ada dua prinsip yang dikemukakan di sini. Pertama, prinsip umum. Kedua, prinsip khusus.

Yang dimaksud dengan prinsip umum ini ialah:

1. Prinsip relevansi. Kurikulum yang kita rancang dan kembangkan harus 
relevan dengan kebutuhan peserta didik

2. Prinsip fleksibilitas. Kurikulum yang kita rancang dan kembangkan perlu bersifat adaptif, mampu menyesuaikan diri dengan konteks pembelajaran. Pertimbangan konteks di sini mencakup aspek ruang dan waktu, sosial, budaya dan dinamika keagamaan.

3. Prinsip kontinuitas. Kurikulum yang kita rancang dan kembangkan harus memungkinkan peserta didik lebih sanggup mengembangkan potensinya kelak dalam rencana belajar berikutnya (prinsip belajar sepanjang hayat).

4. Prinsip praktis. Kurikulum sebaiknya mudah digunakan dengan alat sederhana dan biaya relatif murah,

5. Prinsip efektivitas. Efektivitas sebuah kurikulum harus dilihat dari sejauhmana perubahan hidup dialami oleh peserta didik, sebagaimana nampak dalam kehidupan dan karya pelayanannya.

Kedua, prinsip khusus, yang terkait dengan sejumlah komponen dari kurikulum itu sendiri, yakni tujuan, isi atau bahan pengajaran, metode pembelajaran, media dan alat pembelajaran serta kegiatan evaluasi pembelajaran. Jadi, kurikulum bukan hanya daftar mata pelajaran atau pokok-pokok pengajaran. Lebih dari itu. Bagaimanakah kita mengembangkan masing-masing komponen itu.

\section{Kurikulum Pendidikan Agama Islam Berbasis Kemajemukan}

Pendidikan adalah salah satu bentuk perwujudan kebudayaan manusia yang dinamis dan sarat perkembangan, karena itu perubahan atau perkembangan pendidikan adalah hal yang memang seharusnya terjadi sejalan dengan perubahan budaya kehidupan. Perbaikan pendidikan ini mengandung konsekuensi akan adanya penyempurnaan atau perbaikan kurikulum pendidikan agama Islam. Hal ini dimaksudkan untuk mengantisipasi kebutuhan dan tantangan masa depan dengan diselaraskan terhadap perkembangan kebutuhan dunia usaha atau industri, perkembangan dunia kerja, serta perkembangan ilmu pengetahuan, teknologi, dan seni. Konsep yang sekarang banyak diwacanakan oleh banyak ahli adalah kurikulum pendidikan berbasis pluralisme.

Konsep pendidikan pluralisme adalah pendidikan yang berorientasi pada realitas persoalan yang sedang dihadapi bangsa Indonesia dan umat manusia secara keseluruhan. Pendidikan pluralisme digagas dengan semangat besar "untuk memberikan sebuah model pendidikan yang mampu menjawab tantangan masyarakat pasca modernisme".

1. Pendidikan Islam berbasis pluralisme mempunyai beberapa karakter sebagai berikut;

2. Pendidikan Islam harus mempunyai karakter sebagai lembaga pendidikan umum yang bercirikan Islam.

3. Pendidikan Islam juga harus mempunyai karakter sebagai pendidikan yang berbasis pada pluralitas..

4. Pendidikan Islam harus mempunyai karakter sebagai lembaga pendidikan yang menghidupkan sistem demokrasi dalam pendidikan.

Perlunya membentuk pendidikan Islam berbasis pluralisme tersebut, sekali lagi merupakan suatu inisiasi yang lahir dari realitas sejarah pendidikan khususnya di Indonesia yang dianggap gagal dalam membangun citra kemanusiaan. Untuk merealisasikan cita-cita pendidikan yang mencerdaskan seperti tersebut, lembaga pendidikan Islam perlu menerapkan sistem pengajaran yang berorientasi pada penanaman kesadaran pluralisme dalam kehidupan. Adapun beberapa program pendidikan yang sangat strategis dalam menumbuhkan kesadaran pluralisme 
adalah: pendidikan sekolah harus membekali para mahasiswa atau peserta didik dengan kerangka (frame work) yang memungkinkannya menyusun dan memahami pengetahuan yang diperoleh dari lingkunganya (UNESCO, 1981).

Karena masyarakat kita majemuk, maka kurikulum PAI yang ideal adalah kurikulum yang dapat menunjang proses siswa menjadi manusia yang demokratis, pluralis dan menekankan penghayatan hidup serta refleksi untuk menjadi manusia yang utuh, yaitu generasi muda yang tidak hanya pandai tetapi juga bermoral dan etis, dapat hidup dalam suasana demokratis satu dengan lain, dan menghormati hak orang lain.

Selain itu, perlu kiranya memperhatikan kurikulum sebagai proses. Ada empat hal yang perlu diperhatikan guru dalam mengembangkan kurikulum sebagai proses ini, yaitu; (1) posisi siswa sebagai subjek dalam belajar, (2) cara belajar siswa yang ditentukan oleh latar belakang budayanya, (3) lingkungan budaya mayoritas masyarakat dan pribadi siswa adalah entry behaviour kultur siswa, (4) lingkungan budaya siswa adalah sumber belajar (Hamid, op cit: 522). Dalam konteks deskriptif ini, kurikulum pendidikan mestilah mencakup subjek seperti: toleransi, tema-tema tentang perbedaan ethno-kultural dan agama: bahaya diskriminasi: penyelesaian konflik dan mediasi: HAM; demokrasi dan pluralitas; kemanusiaan universal dan subjek-subjek lain yang relevan.

Bentuk kurikulum dalam pendidikan agama Islam hendaknya tidak lagi ditujukan pada siswa secara individu menurut agama yang dianutnya, melainkan secara kolektif dan berdasarkan kepentingan bersama. Bila selama ini setiap siswa memperoleh pelajaran agama sesuai dengan agamanya, maka diusulkan agar lebih baik bila setiap siswa SLTP-PT memperoleh materi agama yang sama, yaitu berisi tentang sejarah pertumbuhan semua agama yang berkembang di Indonesia. Sedangkan untuk SD diganti dengan pendidikan budi pekerti yang lebih menanamkan nilai-nilai moral kemanusiaan dan kebaikan secara universal. Dengan materi seperti itu, di samping siswa dapat menentukan agamanya sendiri (bukan berdasarkan keturunan), juga dapat belajar memahami pluralitas berdasarkan kritisnya, mengajarkan keterbukaan, toleran, dan tidak eklusif, tapi inklusif (Darmaningtyas, 1999: 165).

Amin Abdullah (2001: 13-16) menyarankan "perlunya rekontruksi pendidikan sosial-keagamaan untuk memperteguh dimensi kontrak sosialkeagamaan dalam pendidikan agama". Dalam hal ini, kalau selama ini praktek di lapangan, pendidikan agama Islam masih menekankan sisi keselamatan yang dimiliki dan didambakan oleh orang lain di luar diri dan kelompoknya sendirijadi materi pendidikan agama lebih berfokus dan sibuk mengurusi urusan untuk kalangan sendiri (individual atau private affairs). Maka, pendidikan agama Islam perlu direkontruksi kembali, agar lebih menekankan proses edukasi sosial, tidak semata-mata individual dan untuk memperkenalkan konsep social-contract. Sehingga pada diri peserta didik tertanam suatu keyakinan, bahwa kita semua sejak semula memang berbeda-beda dalam banyak hal, lebih-lebih dalam bidang akidah, iman, credo, tetapi demi untuk menjaga keharmonisan, keselamatan, dan kepentingan kehidupan bersama, mau tidak mau, kita harus rela untuk menjalin kerjasama (cooperation) dalam bentuk kontrak sosial antar sesama kelompok warga masyarakat.

Pendek kata, agar maksud dan tujuan pendidikan agama Islam berbasis pluralisme dapat tercapai, kurikulumnya harus didesain sedemikian rupa dan favourable untuk semua tingkatan dan jenjang pendidikan. Namun demikain, pada 
level sekolah dasar dan menengah adalah paling penting, sebab pada tingkatan ini, sikap dan perilaku peserta didik masih siap dibentuk. Dan perlu diketahui, suatu kurikulum tidak dapat diimplementasikan tanpa adanya keterlibatan, pembuatan dan kerjasama secara langsung antara para pembuat kurikulum, penulis text book dan guru.

Langkah-langkah yang perlu diperhatikan untuk mengembangkan kurikulum PAI berbasis pluralisme di Indonesia, adalah sebagai berikut;

1. Mengubah filosofi kurikulum dari yang berlaku seragam kepada filosofi yang lebih sesuai dengan tujuan, misi, dan fungsi setiap jenjang pendidikan dan unit pendidikan.

2. Kurikulum harus yang berisikan fakta, teori, generalisasi kepada pengertian yang mencakup pula nilai, moral, prosedur, dan ketrampilan yang harus dimiliki generasi muda.

3. Teori belajar yang digunakan dalam kurikulum masa depan yang memperhatikan keragaman sosial, budaya, ekonomi, dan politik.

4. Proses belajar yang dikembangkan harus berdasarkan proses yang memiliki tingkat isomorphism yang tinggi dengan kenyataan sosial. Artinya, proses belajar yang mengandalkan siswa belajar individualistis harus ditinggalkan dan diganti dengan cara belajar berkelompok dan bersaing secara kelompok dalam suatu situasi positif.

5. Evaluasi yang digunakan haruslah meliputi keseluruhan aspek kemampuan dan kepribadian peserta didik, penggunaan alternatif assesment (portfolio, catatan, observasi, wawancara) dapat digunakan.

Di samping perlunya memperhatikan langkah-langkah itu, untuk menuju sebuah PAI yang menghargai pluralisme, sebenarnya selain aspek kurikulum yang harus didesain, sebagaimana telah penulis uraikan, aspek pendekatan dan pengajaran harus pula di perhatikan. Pola-pola lama dalam pendekatan atau pengajaran agama harus segera dirubah dengan model baru yang lebih mengalir dan komunikatif. Aspek perbedaan harus menjadi titik tekan dari setiap pendidik.

\section{Daftar Pustaka}

Allen, Dougles, 1978, Structure and Creativity in Religion. The Houge the Netherlands: Mountan Publisher.

Arkoun, Mohammed, 2001, Islam Kontemporer: menuju Dialog antar agama, Yogyakarta: Pustaka Pelajar.

Abdullah, Amin, M., (1999), Studi Agama: Normativitas atau Historisitas, Yogyakarta: Pustaka Pelajar.

Azra, Azyumardi, 1998, Esai-esai Intelektual Muslim dan Pendidikan Islam, Tradisi dan Modernisme Menuju Milenium Baru, Jakarta: Logos Wacana Ilmu.

Barnadib, Imam, 1994, Filsafat Pendidikan: Sistem dan Metode, Yogyakarta, Andi Ofset.

Basri, Ghazali at al, (1991), An Integrated Education System In A Multifaith and Multi-Cultural Country, Malaysia: Muslim Yuth Movement Malaysia.

Basuki, Singgih, A., (1999), "Kesatuan dan Keragaman Agama Dalam Pandangan Hazrat Inayat Khan", dalam Jurnal Penelitian Agama, Nomor 21, TH. VIII Januari-April, h. 151.

Beck, Clive, (1990), Better Schools: A Value Perspective, Britain: The Falmer Press, Taylor and Francis ICC. 
Bogdan, Robert, C. and Biklen, Knoop, Sari, Qualitative Research for Education, an Introduction to Theory and Methode, Boston: Allyn and Bacon, 1993: 2

Bulac, Ali, 1998, "The Medina Document", dalam Charles Kurzman (eds.), Liberal Islam, New York: Oxford University Press.

Darmaningtyas, (1999), Pendidikan Pada Dan Setelah Krisis, Yogyakarta: 1999.

Dawam, Ainurrofiq, 2003, Emoh Sekolah, Yogyakarta: Inspeal Ahimsa Karya Press.

Dewey, John, 1916, Democracy and Education, New York: Macmillan.

Durkheim, E., 1961, Moral Education, New York: The Free Press.

Effendy, Bachtiar, 2001, Masyarakat Agama dan Pluralisme Keagamaan, Yogyakarta: Galang Press.

Engineer, Ali, Asghar, 2001, On Developing Theology of Peace In Islam, Islam and Modernity. Oktober.

Esack, Farid, 2000, Qur'an, Liberation, and Pluralism, Diterjemahkan oleh: Watung A. Budiman, Bandung: Mizan.

Faruqi, Isma'il dan al-Faruqi, Lamnya, Lois, 1986, The Cultural Atlas of Islam, New York: Macmillan Publishing Company.

Hasan, Hamid, S., (2000), "Pendekatan Multikultural Untuk Penyempurnaan Kurikulum Nasional”, dalam Jurnal Pendidikan dan Kebudayaan, Jakarta, Edisi Bulan Januari-November, h. 510-524.

Hick, John, Philosophy of Religion, New Delhi: Prentice Hall, 1963.

Hidayat, Komaruddin, 1998, Tragedi Raja Midas, Jakarta: Paramadina.

Khisbiyah, Yayah at al., (2000), "Mencari Pendidikan Yang Menghargai Pluralisme" dalam Membangun Masa Depan Anak-anak Kita, Yogyakarta: Kanisius.

Mouw, Richard J and Griffon, Sander, 1993, Pluralism and Horizon, Grand Rapids: William B. Eerdmans Publishing Company.

Mulkhan, Munir, Abdul, (2002), Nalar Spritual Pendidikan, Yogyakarta: Tiara Wacana.

Nasr, Hossein, Sayyed, (1980), Living Sufism, London: Unwin Paperback.

Rachman, Munawar, , Budi, (2001), Islam Pluralis, Jakarta: Paramadina.

Rahmat, Jalaluddin, 1997, Islam Inklusif, Bandung: Mizan.

Rodger, Alex R., 1982, Educational and Faith in Open Society, Britain: The Handel Press.

Sealy, John, (1985), Religious Education Philosophical Perspective, London: George Allen \& Unwin.

Shihab, Alwi, Islam Inklusif, Bandung: Mizan.

Siradj, Aqiel, Said, (1999), Islam Kebangsaan: Fiqih Demokratik Kaum Santri, Jakarta: Pustaka Ciganjur.

Smith, W. C. Toward Theology: Faith and the Comparative History of Religion, London\&Basingstoke: The Macmillan Press, 1981.

Sumartana at al., (2001), Pluralisme, Konflik, dan Pendidikan Agama di Indonesia, Yogyakarta: Pustaka Pelajar.

Tilar, H. A. R., 2000, Paradigma Baru Pendidikan Nasional, Jakarta: Rineka Cipta.A 
Audrey \& S. Howard Nicholls, dalam Developing a Curriculum: A Practical Guide New Edition (London: George Allen \& Unwin, 1982)

Prof. S. Nasution, Kurikulum Dan Pengajaran (Bina Aksara, 1989)

Nana Syaodih Sukmadinata, Pengembangan Kurikulum: Teori dan Praktek (Remaja Rosdakarya, 1997), h. 150-155. 